\title{
Transformation of the column order in the Baroque architecture in St. Petersburg of the XVIII century
}

\author{
Ekaterina Vozniak $^{1, *}$, Tatyana Slavina $^{1}$ and Anna Kopytova ${ }^{2}$ \\ ${ }^{1}$ Saint Petersburg State University of Architecture and Civil Engineering (SPSUACE), 2-nd \\ Krasnoarmeiskaya St. 4, 190005 St. Petersburg, Russia \\ ${ }^{2}$ Tyumen Industrial University, Volodarskogo str., 38, Tyumen, 625000, Russia
}

\begin{abstract}
The forms and proportions of the Baroque column order of the buildings in St. Petersburg of the XVIII century differ substantially from the Western European canonical designs. The independent order system was created in each historical period under the influence of European architectural concepts, local style preferences, and creative choice of architects, and is of undoubted interest to both historians of architecture and restorers of historic buildings. The authors made a comparative analysis of the construction and drawing of architectural orders of buildings in St. Petersburg with architectural orders of classical works of the Renaissance, architectural works of the XVII - XVIII century. The process of gradual formation and modification of the column order in the architecture of St. Petersburg in the first half of the XVIII century is expounded. The main features of the construction of architectural orders during the Peter's, Ann's, and Elizabethan Baroque periods are revealed.
\end{abstract}

\section{Introduction}

The classical column order is the most important for the formation of historical architecture. Its gradual development in Russia in the XVIII century was a rather complicated and contradictory process. The order classical system is based on the works of M. Vitruvius, J. Vignola, A. Palladio, etc. The significant differences between canonical examples of the Renaissance column orders and buildings of St. Petersburg in the 18th century are evident in with a detailed examination. This fact was not so conspicuous in architectural and art history literature.

For architects of the XVIII - XIX centuries, the column order was a key element [1]. The column order was the core, the basis of the classical theory of architecture [2]. It was accepted to begin study of architectural science with this. The design of the building was based on the definition of the type of order corresponding to it. The design began with architectural details of the order, and extended then to all elements of the building. The image of order reflected the architect's views on the theory of architecture, his attitude to style, character and

\footnotetext{
* Corresponding author: vozniak65@mail.ru
} 
education. What was the reason of such significant differences in the drawing of orders in St. Petersburg, why and how they changed during the XVIII century.

\section{Materials and methods}

The column order, like the all European architecture, was brought by Peter the Great and his companions. At the contradictory times of the emergence of a new architecture for Russia, to St. Petersburg the high class architects (J.-B. Leblond and N. Michetti) were invited, here worked foreign specialists who became professional architects already here in the city under construction (D. Trezzini) as well the old Russian masters, who did not know the orders and Russian students who are mastering a new science. All these architects encountered builders and artisans who did not know any classical elements, but very quickly trained, ready for architectural innovation. The architectural forms of the Peter's Baroque are extremely different in terms of design and execution: from high-quality author compositions to simplified coarse elements. Classical books by G. Vignola, A. Palladio and F.-N. Blondel were brought to St. Petersburg in the first decade of the 18th century and were well known to architects [3, p.26; 4, p.32]. Nevertheless, the classical architecture of the order in the most advanced at that time interpretation of F.-N. Blondel did not get accustomed to Petersburg. The order turned out to be interpreted by the German theoretician Leonard Sturm [5] became the closest in detalization to the St. Petersburg in first halve XVIII century. But even the order on Sturm's engravings is still much more classical. Rustic pilasters and a number of other elements correspond the engravings of the French architect O.Sh. D'Avillet, whose book was supplemented by J.-B. Leblon in 1710 [6]. In this work, you can find many elements close to St. Petersburg's architecture; however, the flat and graphic drawing of Russian orders is very different from the French samples. The authors carried out a comparative analysis of the construction and drawing of orders of buildings in St. Petersburg with classical examples of the Renaissance (J. Vignola, A. Palladio), as well with orders from architectural works of the 17 th and 18th centuries (L. Sturm, O.-S. D'Avillier, J.-F. Bolndel, J.-F. Neforge, etc.), and also compared the construction of orders of various architects of St. Petersburg of the 18th century among each other.

\section{Results}

In the Peter's baroque period the order has more planar and stretched proportions. The often used pilasters were distinctive feature of this period. Columns used rare, semi-columns never used. Perhaps this was determined by the difficulty of manufacturing column body with entasis. It is known that the columns of the entrance porticoes of the Peter and Paul Cathedral were brought from abroad and for several years waited their installation. [7, p.30; 8]. In the philistine's homes even the highest dignitaries, the building of columns was difficult, preference was given to pilasters, as well as pillars from rusts. The proportions of orders could be highly distorted, often orders were stretched in height. So the Tuscan pilasters of the Monplaisir Palace in Peterhof had a ratio of width to height $-1: 12$, which is higher than the proportions of even a complex order. The order also could be shortened, as, for example, it was done on the facade of the Menshikov Palace in St. Petersburg.

The order of this period bears the baroque features (see Fig. 1). Many orders have broken surface, although present compositions along with this method are encountered indivisible. All broken surfaces have small ledges. Broken surfaces could cover all the order, but more often the entablement was broken to the larmier of cornice. A drip molding of the cornice covered the small projections of the pilasters. In this period the baroque reception of the installation of triple pilasters was widely distributed. Two additional pilasters were pressed 
symmetrically along the sides to the main pilaster. This technique created the decorative effect of a beam of pilasters. Orders they liked to combine with rustic elements: a pilaster was lying on a rustic wall or the body of a pilaster was broken by rectangular rusts.

a)

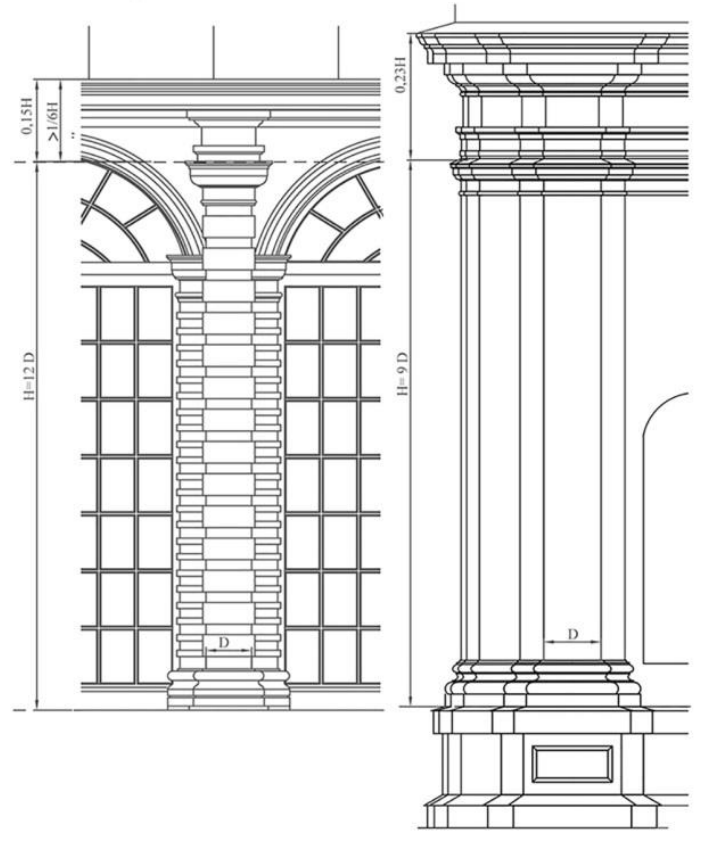

c)

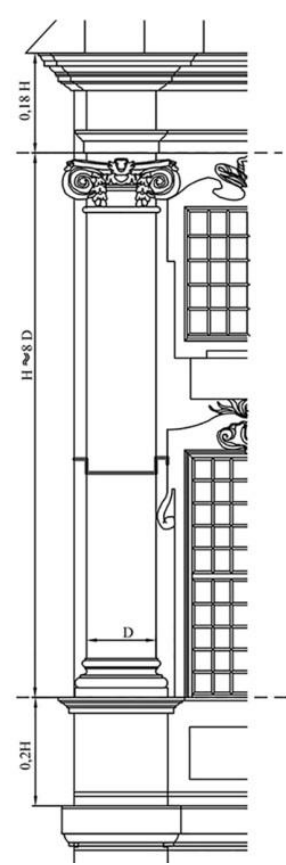

d)

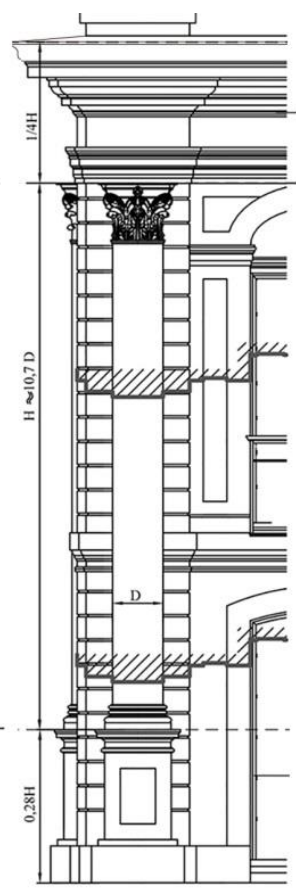

Fig. 1. Peter's baroque orders: a) - Tuscan pilaster on the facade of the Monplaisir Palace in Peterhof, p. 1714-1723, architect. A. Schlüter, I. Braunstein, N. Miketti, b) - Doric Pilasters of the Peter and Paul Cathedral, p. 1713-1733, arch. D. Trezzini, c) - Ionic Pilaster of the Annunciation Church in the Alexander Nevsky Lavra, p. 1717- 1724, architect. D. Trezzini, K. Conrad, T. Schwertfeger, d) Corinthian pilaster of the Hermitage pavilion in Peterhof, p. 1721-1725, architect. I. Braunstein.

During the Peter's Baroque period, the Tuscan and Doric orders are look the same. The proportions of the columns vary from 1:8 to 1:12 widths in height. The triglyph is a distinctive element of the Doric order, it is very rare. Cornices - simple, without dentils or modillions. This intermediate Tuscan-Doric order, due to the simplicity of bulding, was the most widely distributed. The Ionic Order capital was customarily used with a collars in style of Michelangelo, and never made with a classical capital, as it was painted by J. Vignola or A. Palladio. Volutes were decorated with crumbling garlands of flowers. Denticals or modullions never used in this configuration. Cornice over the Ionic order was made with a large ledge in the supporting part, where the classical orders had to have denticals. The most solemn facades were decorated with Corinthian order. The capital is ordinary with different detailing. The cornices could be either simple or with a baroque ledge in the supporting part of the cornice. A Complicated order was applied extremely rarely, only on the upper floors, when the Corinthian pilasters stood below. There were two types of order's basis - Tuscan and Attic. And they put them regardless of the canonical rule, under any order. The pedestal could be done both in order forms and as a simple socole elevation.

After Peter's death, the construction skills of making order system evolution continued [9]. During the Ann's Baroque period (1730s-early 1740), orders became more correct and restrained (see Fig. 2). The best samples of this period have not preserved, and we can analyze them only by fixative and project drawings. Most architects in the interpretation of orders 
followed to the German system, for example L. Sturm. The influence of the treatise "Vollständige Anweisung .." L. Sturm on the architecture of the first half of the XVIII century of St. Petersburg is very large. L. Sturm worked in Wolfenbüttel and Mecklenburg. The architecture of the North German principalities of the early 18th century was very close to the royal customers - to Peter I, his nieces and daughters. The elder sister of the Empress Anna Ioannovna in her marriage became a duchess Meclenburg Swerince. In the documents regulating the training of young Russian architects L. Sturm's book is mentioned several times as the most important [4, c.349]. It is in this treatise that one can find a characteristic drawing of flat triglyphs, Ionic capitals with garlands, cornices with a large ledges in the supporting part.

a)

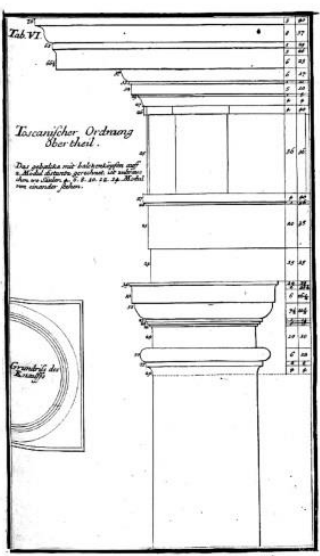

b)

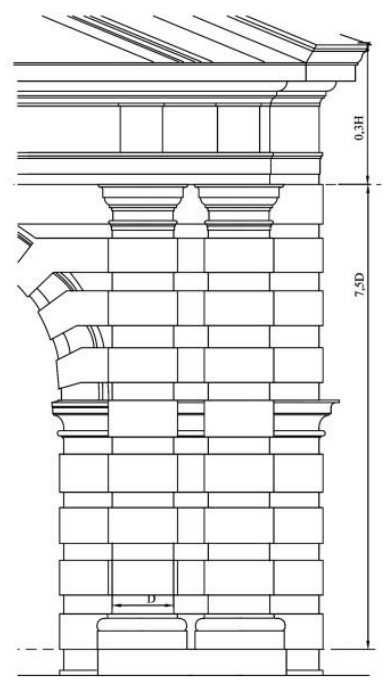

c)

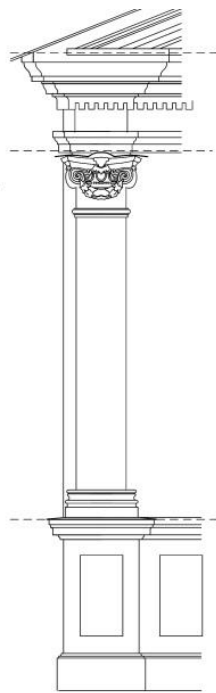

d)

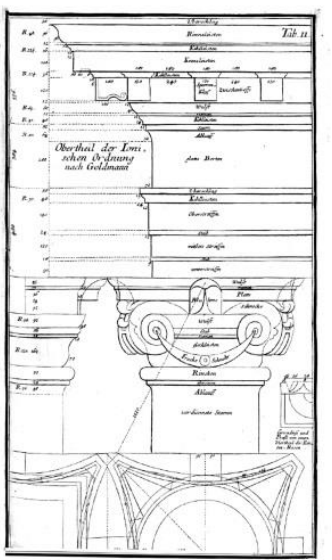

Fig. 2. Orders of the Ann's Baroque: a) - Doric Order of L. Shturm, b) - Doric Order on the Facade of the Ioannovskiy Gate, p. 1738-1740, architect. B.K. von Minich, c) - ionic pilasters of the church of St. Simeon and Anna, p. 1731-1734, architect. M.G. Zemtsov, d) - Ionically the order of L. Sturm.

The proportions of orders in the period of the Ann's baroque became more precise. They could be distorted on the facades of specific buildings, but much less than before. For instance the proportions of the surviving samples of the Ionic order vary from 1:7-1:9 ratio of the diameter of the columns to their height. The facades of buildings were decorated with columns and pilasters, but the prevalence of the pilasters has ceased to be so dominant. The triple pilasters are gone. Pilaster side (rus. raskrepovka) have a small shift, but F.-B. Rastrelli gradually increased size of them. In ordinary buildings, the pilaster sit is finished usually under the eaves slab.

The first four Roman orders used in that period but Composite order have not applied on facades. Doric and Tuscan orders at this time replicated almost identically. Frequently encountered reception of this period is a small shift of architrave, frieze and supporting part of the cornice. This ledge on the frieze was looked like as a simplified triglyph. Cornices were simple, without dentils and modillons. On the columns of the Tuscan order, rustics were possible.

The Ionic order was used on more significant structures. The capital always with a ledges and centres of the volutes connected by the garland with flowers. Cornice is baroque, in the place where the canonical order should have dentils, had a large ledge. Under the cornice of the church of Simeon and Anna there is a chopped belt, reminiscent of the dentils [11]. Perhaps this is one of the first attempts to introduce an element of classical dentils in St. 
Petersburg. The Corinthian order was met in the form of pilasters or in the form of columns on special responsible buildings. So the columns were designed on triumphal arches. This order has always been made with pilasters sides. Tuscan and Attic bases were used for the Doric and Tuscan orders, the Ionic and Corinthian orders had only an attic base. The pedestal could be solved as a plinth wall or as an order pedestal.

During the Elizabethan Baroque period, work of F.B. Rastrelli goes to creative peak. He creates his own order system (see Fig. 3). Other architects of St. Petersburg followed him but draw more restrained compositions. Rastrelli knew the classical theory of the order well, but considered personal creative freedom possible in the baroque transformation of the order. In his draft drawings there are more order canonical elements than those on real buildings. Thus on the drawings you can see modulions and triglyphs, and really these elements were not executed. Freedom of self-expression, combined with local conditions and the level of construction craft, led to the formation of a special architectural order system. A surprising result is a comparison of Rastrelli orders with the orders of Italian and French architects of this period (O.-Sh. D'Avilie, Sh. E. Briso, A. Pozzo, G. Gvarini, etc.). Everyone has deep pilaster sides, there are baroque "bundles" of columns, there is a similarity in distinct elements. But in general, the Rastrelli order is another order, another system for drawing details. The Italian and French architects much more followed adherence to the traditions of the Renaissance. The main thing that differs the order of Elizabethan baroque from European counterparts is a special stylistics of decorativeness: splendor and lightness at the same time.

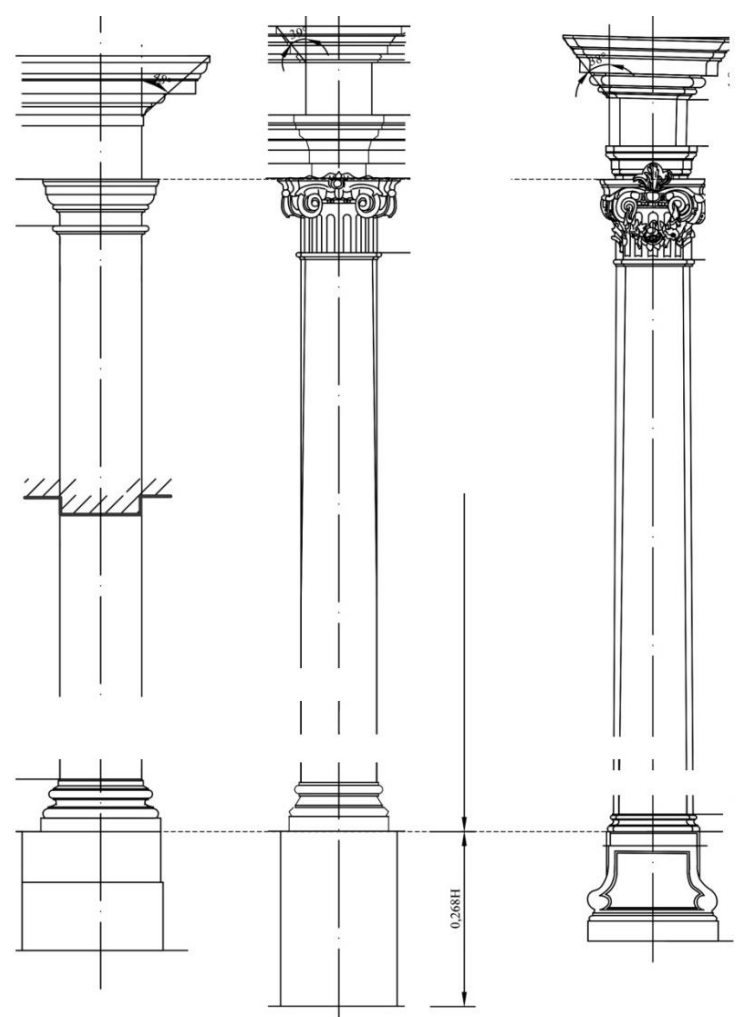

a)

b)

c)

Fig. 3. Column order F. Rastrelli: a) - Doric order, pilasters of the fence of the Smolny Cathedral, $p$. 1748-1764, b) - Ionic order, columns of the 1st floor of the Winter Palace, p. 1754-1762, c) Composite order of the Catherine Palace in Tsarskoe Selo, p. 1752-1757. 
The proportions of Elizabethan baroque orders deviate from the classic designs of J. Vignola and A. Palladio, the order is extended a little. The proportions of the Doric order were from $1: 8$ to $1: 9$, Ionic - from 1:8.5 to $1: 10$, composite - from 1:10 to $1: 11.5$. The specific feature of the Elizabethan Baroque orders is a special drawing of moulds. Classical semicircular Roman mould during this period are drawn differently - in the form of a roller with a characteristic baroque recess on top of the element (see Fig. 4). As a result, the profile drawing of this period is very different from the previous and the subsequent historical stage. Deep shadows strip the round shafts from the rectangular ledges.

a)

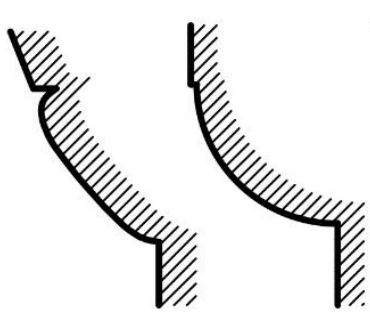

c)

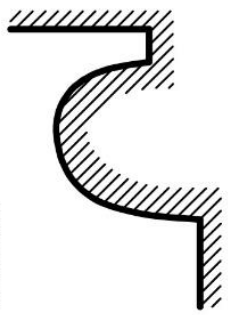

d)

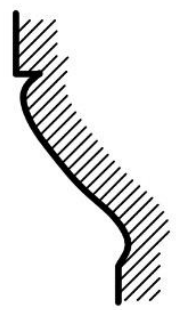

e)

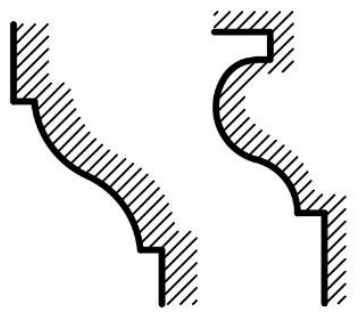

Fig. 4. Comparison of the moulds drawing: a) - Greek echine, b) - Roman quarter shaft, c) Baroque shaft, d) - Greek cyma reversa, e) - Roman heel, e) - Baroque heel.

During the Elizabethan Baroque period, Doric, Ionic, composite and very rarely Corinthian orders were used. The Tuscan columns were apparently too squat and simple for a refined style. Doric order is also rare. F.-B. Rastrelli, even on the first floors of the buildings preferred to put Ionic columns, allowing the installation of the Doric order only on the fence: the Summer Palace of Elizabeth, the Catherine Palace, on the fence of the Smolny Cathedral. The triglyphs were not constructed on the Doric order, triglyphs, modillons and other characteristic elements were not made. The entablature and the pedestal were drawn freely, with large deviations from the order proportions. The Ionic order was widely used during this period. The capital of the Russian baroque Ionic capital is large, always has a collar. On the collar of the ionic capital, Rastrelli profiled the flutes. On the very trunk of the facade columns, the flutes were not made.

The Corinthian order in this era was rarely used. F.-B. Rastrelli did not use this order, preferring to use a composite one. S. Chevakinsky decorated the Corinthian columns on the facades of the St. Nicholas Cathedral. The Corinthian capitals are decorated with the heads of angels. The remaining elements of this order more closely correspond to the drawing of the composite order.

The Composite order was widespread in this period, as the most appropriate decorative style of Elizabethan baroque. Composite order F.B. Rastrelli is easy to confuse with an ionic order. On the capitals of the Composite order Rastrelli there are not acanthus leaves under the volutes. Here is located the collar with the flutes. The centers of the volutes of the Composite order Rastrelli are connected by garlands of flowers. While volutes of Ionic capitals Rastrelli did not decorate with garlands. The base of the columns under all orders during this period is drawn attic. In the Doric order you can see the corresponding it's base very rarely. A lot of columns had a pedestal.

To enhance the decorative effect in Elizabethan baroque, half-columns often leant to the two pilasters. Baroque semi-columns protruded from the wall more than $3 / 4$ of their diameter. The combination of half-columns and pilasters gave a sense of a bundle of columns on the facade. At the corners of facades they put two or four half-columns with pilasters. The obligatory feature of the Elizabethan baroque was a deep pilaster side order. Baroque 
architects advanced the entablature of a column from the surface of the wall. The whole order turned into an elegant high pillar by a complex set of elements.

Orders, executed according to the classical canons, appeared in Russia only after Catherine II came to power. Tastes of society turned to classicism [12]. JB. Wallen-Delamot [13] was invited from the family of the famous Blondels from France. If before this period the baroque tendencies overshadowed the classic order of the Renaissance, in this period there appears a strong desire to develop within the European classicism. Despite the general aspiration of the architects to the canon, the drawing of the orders was still of an individual character. As a result, there is no a single column made in exact accordance with the engravings of Vignola or Palladio. Details of the order were drawn with some generalization or other interpretation. This interpretation is more corresponds the works of J.-F. Bolland and J.-F. Nephorzh, published at this time in France [14, 15]. Orders of early classicism are elegant, individual, they do not have asceticism peculiar to the Palladian direction of some monuments of the subsequent period - strictly classicism.

Orders J.-B. of Wallen-Delamot, A.F. Kokorinov, I.E. Starov quite accurately correspond to the classical orders. A. Rinaldi continued to build a column order with Baroque elements. Gradually, he begins to more accurately observe the proportions, carefully working with the elements, reduces the number of Baroque entablature pilaster sides. To see the dynamics of the process, it is enough to compare his early works of this period (the Chinese Palace, the Sledge hill) and the sample of the end period of early classicism - the Marble Palace. Nevertheless, A. Rinaldi, even in later works, does not put dentills, modillons or brackets on his orders, as baroque masters did.

So gradually, Petersburg architecture entered the mainstream of the European neoclassical development path. Later G. Quarenghi chose a strict neo-palladian order, C. Cameron taught Russian architects classical Greek orders, and in the works of V. Brenna the last "outbreak" of the baroque tendencies of the XVIII century can be seen.

\section{Discussion}

The questions of the origin of the colonial orders systems of the 18th century St. Petersburg remain controversial. If the influence of the works of L. Sturm on the period of the Ann's Baroque can be regarded as sufficiently revealed, but it is quite difficult to determine the limits of F. Rastrelli's creative freedom. The authors state that, despite the acquaintance of F. Rastrelli with the works and samples of Italian, French and German thought of the 18th century, the Rastrelli order is original. Under the influence of local conditions, in the conditions of creative freedom, a decorative system was created, making the St. Petersburg palaces of this period unique to the world culture (see Fig. 5). 
a)

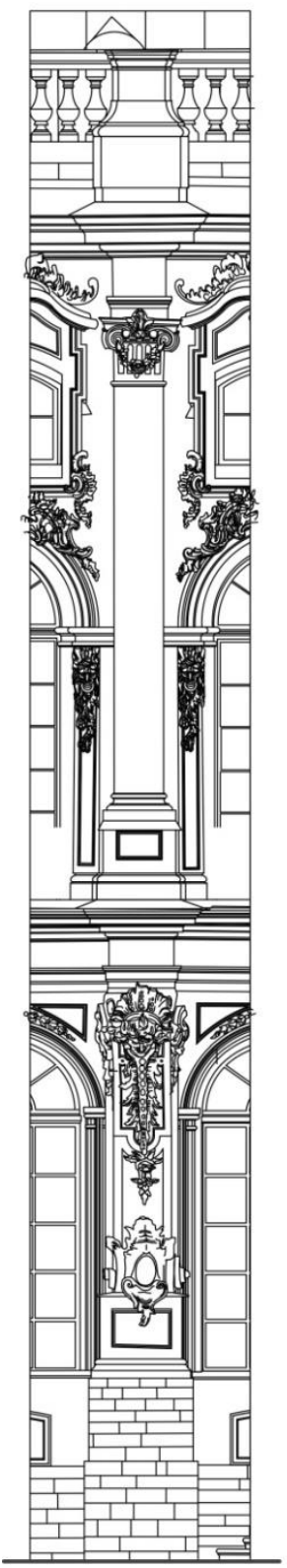

b)
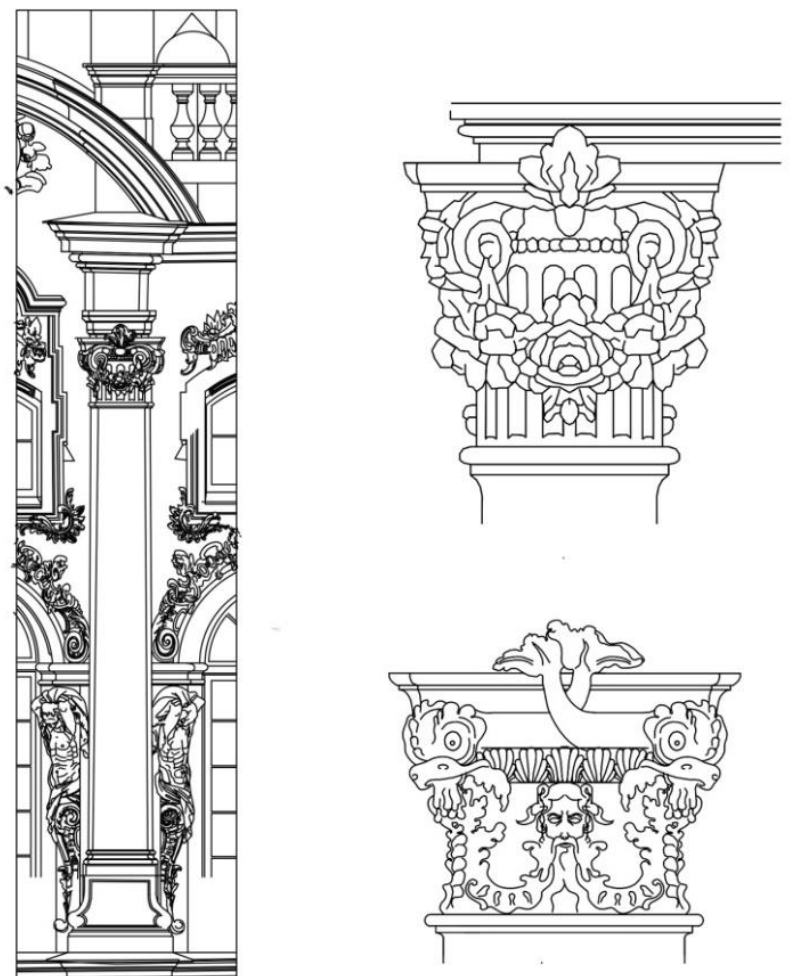

Fig. 5. Decorative decoration of facades by F. Rastrelli: a) - fragments of the facades of the Catherine Palace in Tsarskoe Selo, p. 1752-1757, b) - capitals of Composite orders F. Rastrelli.

\section{Conclusion}

The development of Russian order system in the XVIII century was a complex and contradictory process, somewhat different from the general process of development of world 
cultural thought. During this period, monuments of architecture were created that make up the treasures of Russian culture, such as the Catherine and Winter Palace, the Marble Palace and the Peter and Paul Cathedral. In the XVIII century, the order in Petersburg quickly changed, and in each separate period, a complete and quite complete system of order building was created. Each leading architect, within a certain style, having sufficient creative freedom, created his system of orders and architectural forms. These systems of architectural elements, in themselves, represent a cultural value. Their study allows a closely to understand the architecture of the past, and contributes to the preservation of the historical heritage ful.

\section{References}

1. E.K. Blinova, Izvestia of the RSPU named after A.Ya. AI Herzen: Scientific journal 12(84), 44-51 (2008)

2. Architectural theory: from the Renaissance to the present : 89 essays on 117 treatises. Vol. 1, with a preface by Bernd Evers and an introduction by Christof Thoenes ; in cooperation with the Kunstbibliothek der Staatlichen Museen zu Berlin (Köln, Taschen, 2011)

3. N.A. Evsina, Architectural theory in Russia in the XVIII century, Academy of Sciences of the USSR, Institute of Art History of the Ministry of Culture of the USSR (Nauka, Moscow, 1975)

4. K.V. Malinovsky, St. Petersburg XVIII century (Kriga, St. Petersburg, 2008)

5. L.Ch. Sturm, http://www.e-rara.ch/zut/content/titleinfo/3436152/

6. A.-Ch. Aviler, http://www.e-rara.ch/zut/content/titleinfo/200

7. K.V. Malinovsky, Domenico Trezzini (Krieg, St. Petersburg, 2007)

8. S. Nalivkina, Peter and Paul Cathedral. The history of the restoration of 1999-2003, Akme: Restoration of monuments of architecture, http://www.akme.ru/dek/publ04.htm

9. A.E. Ukhnalev, Proceedings of the Russian State Pedagogical University. AI Herzen 140, 136-148 (2011)

10. K. Malinovsky, Bartolomeo and Francesco Rastrelli (Levsha SPb Publishing year, 2017)

11. E.Yu. Stanyukovich-Denisova, Actual problems of theory and history of art. sci. articles (NP-Print, SPb, 2013)

12. D. Shvidkovsky, France in the Russian Classicism of the 18th Century, Razlib.ru

13. O. Medvedkova, Pinakothek 13-14, 28-34 (2002)

14. J.-F. Blondel, Cours d'architecture, ou Traité de la décoration, distribution \& construction des bâtiments (Paris,chez Desaint, libraire) http://www.erara.ch/zut/content/titleinfo/103727.

15. J.-Fr. Neufforge, Recueil Elementaire d'Architecture 8, 1757-1768, http://www.ub.uniheidelberg.de 